\title{
Sarcoidosis presenting with pleurisy and bilateral pleural effusions
}

\author{
N. McI. JoHNSON \\ M.D., M.R.C.P.
}

N. D. T. MARTIN

B.Sc., M.B. B.S.

\author{
M. W. MCNICOL \\ M.B., F.R.C.P. \\ Department of Cardiothoracic Medicine, Central Middlesex Hospital, London, N.W.10
}

\begin{abstract}
Summary
A patient with acute sarcoidosis is described who presented with pleurisy and bilateral pleural effusions, but no other abnormalities on examination or chest $\mathrm{X}$-ray. This presentation of sarcoidosis is unusual and is discussed.

\section{Introduction}

Pleural involvement is rare in sarcoidosis, but when present is typically found in Negresses with several years' history of multisystem involvement by sarcoidosis (Chusid and Siltzbach, 1974; Sharma and Gordonson, 1975; Wilen et al., 1974; Beekman et al., 1976). A male Negro is described who presented with acute pleurisy and bilateral pleural effusions which had been caused by acute sarcoidosis.
\end{abstract}

\section{Patient details}

A 39-year-old carpenter of Jamaican extraction who has lived in the U.K. for 17 years, presented to the Central Middlesex Hospital in March 1978. He had been completely well until December 1977, when he developed pain medial to his right scapula, and felt lethargic. Since January 1978 he had noted gradually increasing breathlessness, had developed bilateral sub-mammary pleuritic chest pain and a feeling of increasing weakness. He had noted weight loss of $2 \mathrm{~kg}$ over 3 months. He was a nonsmoker and there was no relevant previous medical, family or drug history.

On examination he was a fit negroid male. There were signs of bilateral pleural effusions. His cardiovascular system was normal apart from a 4th heart sound. His liver was palpable but was not pathologically enlarged. Further investigations revealed: $\mathrm{Hb}, 15.9 \mathrm{~g} / \mathrm{dl}$; WBC, $6.6 \times 10^{9} / 1$; ESR, $20 \mathrm{~mm} / \mathrm{hr}$ (Westergren); AST, 40 i.u./l, alanine transaminase, 41 i.u./l; albumin, $39 \mathrm{~g} / \mathrm{l}$; bilirubin, $5 \mu \mathrm{mol} / \mathrm{l}$. Chest X-ray, bilateral pleural effusions (Fig. 1); ECG, inverted $\mathrm{T}$ wave in lead III, considered normal; pleural aspirate volumes-right, 1.81 ; left, $1.31 ;$; protein, $56 \mathrm{~g} / \mathrm{l}$; albumin, $29 \mathrm{~g} / \mathrm{l}$. No bacterial growth. Acellular. Rheumatoid factor positive $1 / 320$ in N pleural fluid, negative in blood. Pleural biopsycollections of large clear cells with small nuclei.옥

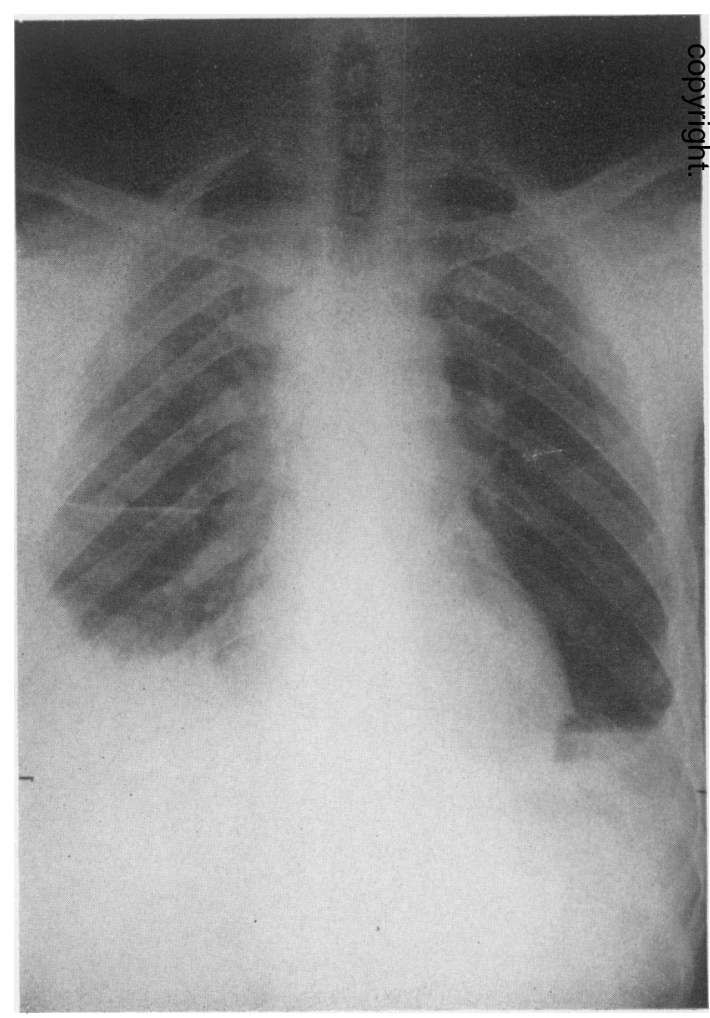

FIG. 1. Chest X-ray showing bilateral pleural effusionstaken after aspiration of left effusion. 
Epithelioid granulomata. Liver biopsy, granulomatous hepatitis.

A provisional diagnosis of sarcoidosis was made on the basis of the pleural and liver biopsies. However, because of the possibility of tuberculosis, a trial of anti-tuberculous chemotherapy was given to which he did not respond. After 6 weeks a mediastinal lymph node biopsy was performed which again confirmed the diagnosis of sarcoidosis (multiple non-caseating epithelioid granulomata with giant cells). The Kveim test which was biopsied at this time was also positive. Thus anti-tuberculous therapy was stopped. It was also noted that he had now developed a harsh apical early systolic murmur which radiated to the axilla. Cardiac catheterization and coronary arteriography were performed because of the possible sarcoid myocardial involvement. These showed haemodynamically insignificant mitral regurgitation. Endomyocardial biopsies showed no evidence of sarcoidosis either with light or electron microscopy.

Since this time he has been treated with prednisone. Within 2 weeks of starting this treatment, he gained complete subjective and objective relief from his pleural disease and he remains well on a low dose of prednisone. His cardiac murmur, although less obvious, persists.

\section{Discussion}

Pleurisy is a rare presenting feature of sarcoidosis and does not always lead to the development of pleural effusion (Gardiner and Uff, 1978). However, a retrospective study of patients with sarcoidosis in whom pleural effusions have occurred has recorded pleuritic pain (Wilen et al., 1974). The incidence of pleural involvement with or without effusions formation is unknown, estimates vary between $1 \%$ and $10 \%$ (Chusid and Siltzbach, 1974; Wilen et al., 1974). In sarcoidosis, pleural effusions are almost always associated with other chest X-ray abnormalities found in sarcoidosis: in one series, 12 of 15 patients with effusions had stage II disease, the remaining 3 had stage III disease (Wilen et al., 1974). One case reported by Chusid, Vieira and Siltzbach (1974) had a large unilateral effusion with no other radiological abnormalities.

There appear to be only 7 previously reported cases of sarcoidosis with bilateral effusions (Wilen et al., 1974; Beekman et al., 1976). The combination of presenting symptoms of pleurisy and bilateral pleural effusions without evidence of underlying lung disease as seen in the present patient is very unusual. The acuteness of his illness is unusual because in one series the shortest history was greater than one year (Chusid and Siltzbach, 1974). Most authors agree that the typical patient with sarcoidosis who is likely to develop pleural involvement is a Negress with several years' history of multisystem involvement by sarcoidosis (Chusid and Siltzbach, 1974; Sharma and Gordonson, 1975). It is of interest that the present patient had generalized disease as shown by hepatic involvement; his effusions were exudates, and those previously recorded are almost equally divided between transudates and exudates (Wilen et al., 1974; Beekman et al., 1976).

Response to corticosteroids was rapid, the effusions having previously failed to resolve spontaneously as they had been reported to do in up to $50 \%$ of patients (Sharma and Gordonson, 1975).

Although the authors were suspicious of papillary muscle sarcoid infiltration being the cause of the mitral regurgitant murmur (Roberts, McAllister and Ferrans, 1977), extensive investigations failed to confirm this.

\section{Acknowledgments}

We are indebted to Dr D. J. Coltart, M.D., M.R.C.P., Consultant Cardiologist, St Thomas's Hospital, London, S.E.1., for performing the cardiac investigations on this patient.

\section{References}

Beekman, J.F., Zimmet, S.M., Chun, B.K., Miranda, A.A. \& KATZ, S. (1976) Spectrum of pleural involvement in sarcoidosis. Archives of Internal Medicine, 136, 323.

Chusid, E.L. \& Siltzbach, L.E. (1974) Sarcoidosis of the pleura. Annals of Internal Medicine, 81, 190.

Chusid, E.L., Vieira, L.O.B.D. \& Siltzbach, L.E. (1974) Sarcoidosis of the pleura. In: Proceedings of the VI International Conference on Sarcoidosis, pp. 373-378. Iwai and Hosoda, University Park Press.

GaRdiner, I.T. \& UFF, J.S. (1978) Acute pleurisy in sarcoidosis. Thorax, 33, 124.

Roberts, W.C., McAllister, H.A. \& Ferrans, V.J. (1977) Sarcoidosis of the heart. A clinico-pathologic study of 35 necropsy patients (Group I) and review of 78 previously described necropsy patients (Group II). American Journal of Medicine, 63, 86.

Sharma, O.P. \& Gordonson, J. (1975) Pleural effusions in sarcoidosis: a report of six cases. Thorax, 30, 95.

Wilen, S.B., Rabinowitz, J.G., Ulreich, S. \& Lyons, H.A. (1974) Pleural involvement in sarcoidosis. American Journal of Medicine, 57, 200. 